\title{
THE RELATION BETWEEN COGNITIVE ABILITY AND PSYCHOLOGICAL READINESS OF SEMI-SKILLED EMPLOYEES IN THE SOUTH AFRICAN MINING INDUSTRY
}

\author{
M L WATKINS \\ A ELLIOT \\ Department of Industrial Psychology \\ University of South Africa
}

\begin{abstract}
OPSOMMING
Politieke verandering het veral in die Suid-Afrikaanse mynbedryf, gelei tot ' $n$ behoefte aan die toepassing van kultuurbillike toetse vir die doeleindes van regstellende aksie. Hierdie toetse word toegepas om kognitiewe vermoë te meet en daar word wyd aanvaar dat dit positief met werksprestasie korreleer. Die vraag het ontstaan of hierdie toetse daartoe in staat is om sielkundige gereedheid om te presteer, voorspel soos geïmpliseer deur Hernstein en Murray (1994) se werk oor die "Bell Curve". In hierdie studie is geen betekenisvolle verband tussen kognitiewe vermoë en sielkundige gereedheid om te presteer, gevind nie. Daar word dus steun vir 'n multi-dimensionele benadering tot die bestudering van intelligensie, gevind.
\end{abstract}

\section{ABSTRACT}

Political change has, especially in the South African mining industry, created the need for the application of culturefair tests with the view of affirmative action. These tests are especially applied to measure cognitive ability, which is widely accepted to be positively correlated with work performance. The question arose whether cognitive tests are able to predict psychological readiness to perform as implicated by Hernstein and Murray's (1994) work on the "Bell Curve". In this study, no meaningful relation between cognitive ability and psychological readiness was found. This reflects some support for a multi-dimensional approach to the study of intelligence.

Political change in South Africa, followed by the demand to implement affirmative action as a compensatory measure for previous deprivation, stimulated many attempts at identifying training and development potential among employees who had been exposed to an inferior educational system. In these attempts, especially the South African mining industry sought to identify psychological tests to measure abilities among employees with the view of exposing "successful" candidates to adult education, advancement and upliftment. Research on the cross-cultural comparability of psychological tests in South Africa is however, still very limited. The formulation of a new constitution for the country which ensures equality before the law, stimulated an awareness of psychological practices which potentially could be discriminatory in nature. This incited a great deal of criticism againts the utilisation of psychometric tests. In view of a literature survey of caveats regarding crosscultural comparability, Abrahams (1994) called for the prohibition of intelligence and personality tests and recommended that the ability to perform tasks, should be considered as the only criterion for work success. She however fails to explain methodological problems involved in previous research on psychometric testing in South Africa. Based on the data of very disparate education departments and schools for different races, Owen (1992) converged to the conclusion that the Raven Progressive Matrices Test is (regardless of its culture-fair nature) unsuitable for developing common norms for standard seven pupils. This is ascribed to differences between group means, but it should be borne in mind that most research on psychometric testing in South Africa was done in an educational system with diverse educational standards. In view of the significance of environmental influences on the development of cognitive abilities, it is quite evident that significant differences between test scores of different racial groups would be measured. These differences are nevertheless ascribed to inherent characteristics of psychometric measures rather than the characteristics of the data which were utilized in the research. The integration of different learning environments into a single educational system should however, stimulate uniformity of standards as a result of which differences between the test scores of racial groups, may well diminish in future. It would thus be premature to reject psychometric testing as a discriminative practice at a very early stage of the transformation process in South Africa. Many organisations have regardless of criticism used culture-fair, cognitive tests as measures of potential job success among employees who had been deprived of proper education.

Hernstein and Murray's (1994) controversial, but best selling "Bell Curve" refers to studies in which correlations of up to 0,53 between job performance and cognitive test scores were found and concludes that the g-factor is the key to work success. Against this background, and evidence of differences between the mean IQ-scores of racial groups, the authors claim that status stratification in society is largely the result of IQ differences and specifically, heritability (Metzler, 1995). This elicited a heated debate in American Society and on the information highway in which the work was, on the whole, dismissed as statistically unsound (Case, 1996), misleading, unacceptable to psychologists (Elias, 1996) and a misuse of the concept "hereditability" (Metzler, 1995). Irrespective of critique levelled at the book, firm support for many aspects of the work can be found in a manifesto which was actively discussed on the internet since 1995. In an electronic document which was prepared by Rogers (1996), no less than fifty researchers in the field of intelligence, support inter alia the notion that cognitive ability or intelligence is a general mental capacity that involves the ability to reason, plan, solve problems, think abstractly, comprehend complex ideas, learn quickly and learn from experience. It reflects a broad capability for comprehending one's surroundings, making sense of stimuli or "figuring out" what to do. This implies that intelligence is more than the narrow academic skill of book learning. They also postulate that a positive relation between cognitive ability and work performance do exist, intelligence can be measured and that intelligence tests measure it well.

Should a positive relation between cognitive ability and work performance exist as being widely accepted, this relationship should also manifest itself in employees' psychological readiness to perform work-related tasks. 
The importance of psychological readiness, as a component of "job maturity" (cf. Hersey and Blanchard, 1980), has been widely publicized by organisational psychologists (cf. Campbell and Pritchard, 1976; Porter and Lawler, 1968; Vroom, 1964). Maslow's (1954) classical theory of human development describes psychological maturation as a process in which people strive to satisfy lower and higher order needs. This notion was strongly supported by; (a) Argyris's (1962) work on individual growth and development from a state of passiveness and dependence, towards psychological states of higher activity and autonomy; (b) Herzberg's (1966) "hygiene factors" and "motivators"; and (c) McClelland's (1961) theory that high achievers strive towards challenging, attainable goals and tend to focus on performance and feedback rather than rewards. These theories inspired Hersey and Blanchard (1980) to follow an integrative approach to describing employee behaviour at four growth stages or "maturity" (M1 to M4) levels which represent various combinations of task and psychological readiness to accept work challenges.

At the M1-level, task readiness is characterised by limited task related experience and knowledge which restrict employees' abilities to autonomously solve problems, make decisions and meet deadlines. Psychological readiness at this level manifests itself in either unwillingness to perform (especially under conditions of change) or uncertainty, which would require external control and a great deal of structure on how, when and where the work should be done. This is ascribed to the dominance of the need for "survival" which can be satisfied by work related structure. The M2-level consists of a situation in which the employee, on the whole, remains to be incompetent (unable) to perform, but a great deal of confidence and willingness to strive towards task related objectives is demonstrated. Although a great deal of structure would remain to be important, emerging social needs would require that managers and supervisors explain why certain tasks are being performed, combined with high levels of emotional support. Quite different from the previous stages, M3employees are competent, but they tend to be somewhat uncertain whether the correct course of action is always being taken. Dominant ego-needs would require facilitative behaviour by superiors in which the importance of the employee's contributions to decision-making processes are recognized. M4-employees are competent and confident (able and willing) to perform their work efficiently, therefore feelings of selfactualization in the work context tend to emerge. This would require that managers delegate work to employees who are autonomously able to make decisions and strive towards the attainment of goals.

Systematic development through the above stages requires a simultaneous change in managerial style. This would entail various combinations of high and low directive and supportive behaviour. Although Hersey and Blanchard postulates that growth should be facilitated by means of behaviour modification techniques and effective leadership, the importance of individuals' innate potential to develop towards the so-called "M4"-level, cannot be ignored.

Attempts at finding empirical support for the theory have yielded mixed results (cf. Blank, Weitzel and Green, 1986). In view of the robust, prescriptive nature and lack of rigorous empirical support, the theory is viewed to, at best, possess face validity (Vecchio, 1987), but if nevertheless emphasizes the importance and relevance of task and psychological readiness for work success.

The purpose here, is not to elicit yet another South African "issue to grapple with", but to find some empirical support that cognitive ability manifests itself in work performance as reflected in psychological readiness to perform. The question however, arises whether cognitive ability can be used as a predictor of "social worth" as implicated by Hernstein and Murray's work. Should this hold true, cognitive ability should also manifest itself in psychological readiness to perform work related tasks. A meaningful relation between these variables should certainly contribute to finding a solution to the comparability problem in that the measurement of psychological readiness, would be somewhat redundant for identifying potential successful employees. Against this background, the hypothesis is stated that cognitive ability manifests itself in higher levels of psychological readiness.

\section{METHOD AND PROCEDURE}

\section{Subjects}

More than 8000 unskilled employees of a large, South African mining company were tested by means of the Standard Raven Progressive Matrices with the view of identifying candidates for adult education and upliftment. From the larger population, 189 black, male, subjects were selected from various organisational units of four mines within the company. All subjects included in the study were exposed to further training and development, followed by employment in semi-skilled positions. Although the subjects had completed their training at different times since 1993, the sample was drawn from those who had received an above-average performance rating before the research commenced. The performance measure was based on specific job categories, linked to four-point scales which range from "totally incompetent" to "highly competent". In view of a lack of empirical evidence regarding the reliability and validity of the measure, peformance appraisals were only used as a criterion for selecting subjects for the study. The employees' supervisors (one per employee) were requested to assess the psychological readiness of their subordinates.

\section{Measures}

\section{Psychological Readiness Scale}

A questionnaire which was developed by Blank, Weitzel, Blau and Green (1988) was used to assess the extent to which subordinates demonstrated 11 behavioural categories associated with psychological readiness, on a four-point scale. The above researchers originally formulated 30 items which were subjected to factor analysis (principal component analysis with varimax rotation) after which 11 items (see figure 1) and 1 common factor were retained. Adequate internal consistencies of self-, peer and manager ratings (range $=0,79$ and 0,94 ) and concurrent validity with the performance ratings of two independent samples $(r=0,47$ and 0,$64 ; p<0,01)$ were reported.

To what extent does the employee....

$\begin{array}{ll}\text { M1 } & \text { Follow through on job tasks } \\ \text { M2 } & \text { Make job related decisions on his/her own } \\ \text { M3 } & \text { Act conscientiously on the job } \\ \text { M4 } & \text { Know what to do without being told } \\ \text { M5 } & \text { Work hard on the job } \\ \text { M6 } & \text { Try hard to improve on his/her performance on the job } \\ \text { M7 } & \text { Strive to do his/her best on the job } \\ \text { M8 } & \text { Do extra work on the job } \\ \text { M9 } & \text { Take care to do the job right } \\ \text { M10 } & \text { Do a thorough job he/she undertakes } \\ \text { M11 } & \text { Set his/her own job goals }\end{array}$

Figure 1: Items included in the psychological maturity scale (adapted from Blank et al. (1988, p. 232)

The results of exploratory factor analysis are rather heuristic in nature, therefore confirmatory factor analysis was performed on the data which were utilized in this study. The hypothesis was stated that 11 observed variables measure 1 common factor or latent variable (ie. psychological readiness). The Linear Structural Analysis (LISREL viii) programme Jöreskog and Sörbom, 1993) was used to perform the analysis. After following the modification indices by correlating some of the error variances (see figure 2), the results revealed that the data 
fit the theoretical framework sufficiently well (RMSEA $=0,057$; 90 percent confidence interval $=0,030 ; 0,082$ ). The hypothesis that the 11 observed variables are able to measure psychological maturity can therefore, not be rejected. It is, regardless of the subjectivity involved in assessments of this nature, evident that rather small proportions of the variances can be ascribed to random error. A Cronbach Alpha coefficient of 0,95 also reflected highly acceptable internal consistency of the measure.

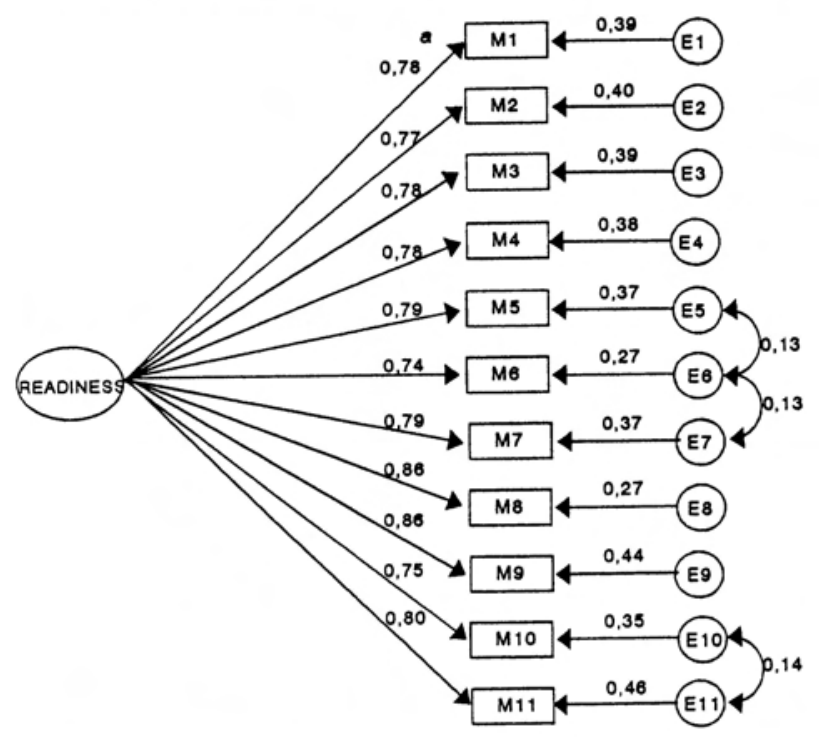

${ }^{\mathrm{a}} \mathrm{p}<0,01$ for all parameter estimates

Figure 2: Confirmatory factor analysis of the psychological readiness scale.

\section{The Standard Raven Progressive Matrices}

The Standard Raven Progressive Matrices is one of the most popular tests which is used to measure general intelligence among adults and children. The popularity of the test can probably be ascribed to the ease of administration and interpretation to which it lends itself. The test consists of sixty multiple-choice items (five sets with twelve items per set) of progressively, increased complexity. It is expected of the respondent to logically complete a matrix pattern from six possible alternatives.

Carpenter, Just and Shell (1990) found that the abilities to induce abstract relations and manage a large set of problemsolving goals, tend to distinguish between high and low scoring subjects on the Raven Progressive Matrices tests. The authors mention several reasons why the Raven tests are appropriate measures in the study cognitive, analytical abilities, namely: (a) The large numbers of items included in the tests lend themselves to experimental analysis of problem solving behaviour; (b) Correlations between Raven Test scores and other measures of intellectual achievement suggest general underlying processes akin to Spearman's g-factor (also see McKenna, 1984) rather than specific aspects of cognitive functioning; (c) The instrument is commonly used in research which requires that language processing be minimized; and (d) Several studies have concluded that the Raven tests measure processes central to analytical intelligence. The tests should however, not be seen as measures of general intelligence due to the exclusion of the verbal component (Owen, 1992). Owen found that, although the Standard Progressive Matrices is suitable for administration among various ethinic groups in South Africa, the test is not totally "culture blind".

In this study, the Standard Raven Matrices was administered under standard test conditions and scored by industrial psychologists from the mining company where the study was conducted. In view of overwhelming empirical evidence regarding the validity and reliability of the test, only the respondents' composite scores were included in further analyses

\section{RESULTS}

The LISREL viii programme was utilised to perform path analysis to determine the cause-and-effect relationship between cognitive functioning and psychological readiness as constructs of "maturity". The correlations (see Table 1) between the Raven score and the items of the Psychological Readiness Scale were used as the input data for Lisrel and the convergence criterion of 0,001 was reached after 7 iterations.

\section{TABLE 1 \\ INTERCORRELATIONS BETWEEN ITEMS OF THE PSY- CHOLOGICAL READINESS SCALE AND THE RAVEN TEST SCORES.}

\begin{tabular}{|c|c|}
\hline M1 & 1,00 \\
\hline M2 & $0,601,00$ \\
\hline M3 & $0,620,571,00$ \\
\hline M4 & $0,620,630,611,00$ \\
\hline M5 & $\begin{array}{lllllll}0,60 & 0,54 & 0,67 & 0,55 & 1,00\end{array}$ \\
\hline M6 & $0,560,570,560,550,751,00$ \\
\hline M7 & $\begin{array}{llllllll}0,60 & 0,63 & 0,64 & 0,58 & 0,71 & 0,75 & 1,00\end{array}$ \\
\hline M8 & $\begin{array}{llllllllllllll}0,68 & 0,64 & 0,67 & 0,67 & 0,71 & 0,65 & 0,70 & 1,00\end{array}$ \\
\hline M9 & $\begin{array}{lllllllllllllll}0,61 & 0,58 & 0,57 & 0,62 & 0,56 & 0,53 & 0,55 & 0,65 & 1,00\end{array}$ \\
\hline M10 & $\begin{array}{llllllllllllll}0,62 & 0,69 & 0,62 & 0,68 & 0,64 & 0,60 & 0,60 & 0,64 & 0,61 & 1,00\end{array}$ \\
\hline M11 & $\begin{array}{lllllllllllllllll}0,54 & 0,63 & 0,56 & 0,62 & 0,59 & 0,58 & 0,55 & 0,62 & 0,54 & 0,73 & 1,00\end{array}$ \\
\hline Raven & 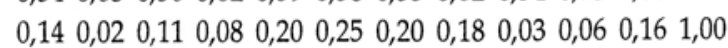 \\
\hline
\end{tabular}

The purpose here, was to estimate the coefficients of linear structural equations with cognitive functioning as the independent variable and psychological readiness as the dependent, latent variable with 11 underlying observed variables. The programme estimates the regression of the independent variable on the dependent variable and random errors as indicated in Figure 3.

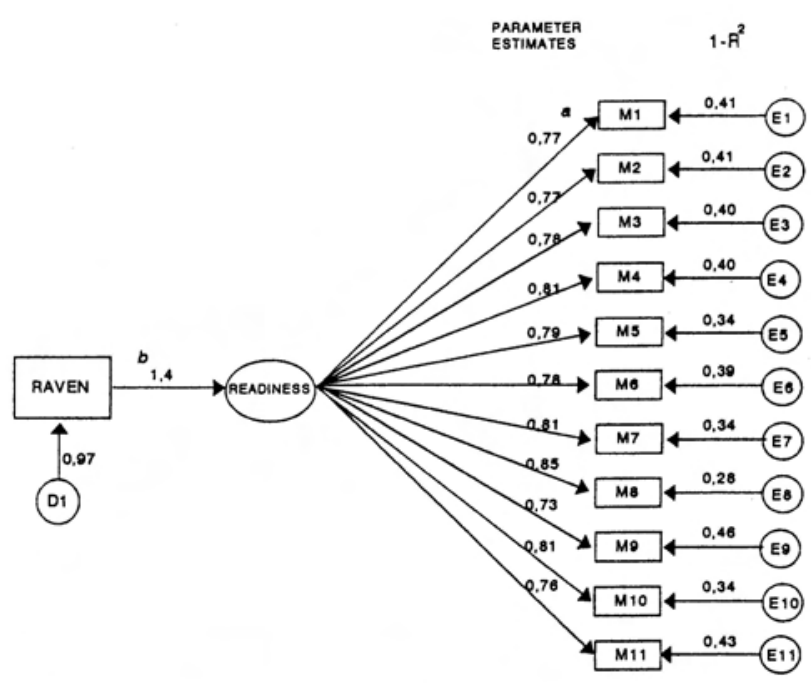

${ }^{\mathrm{a}} \mathrm{p}<0,01$ for all parameter estimates

bparameter estimate not significant

Figure 3: Path analysis with cognitive functioning as independent variable and psychological readiness as dependent, latent variable.

A significant correlation $(\mathrm{r}=0,15 ; \mathrm{p}<0,05)$ between the composite score of the items in the Readiness Scale and the Raven Test was found, which supports the notion of a positve relation between cognitive ability and work performance. However, when cognitive functioning is treated as the independent variable and psychological readiness as the 
dependent latent variable, Figure 3 indicates that the largest proportion of the relation can be attributed to random error. Cognitive functioning is therefore, not a significant predictor of psychological readiness within the proposed model. The fit statistics also revealed poor fit (RMSEA $>0,08$ ) between the theoretical model and the data. This can probably be ascribed to the presence of random errors or exogenous variables outside the theoretical model. The hypothesis of a meaningful relation between cognitive functioning and psychological readiness is therefore, rejected.

\section{DISCUSSION}

Although psychological maturity and cognitive functioning are equally important, these constructs seem to independently contribute to job success. This implies that culture-reduced, cognitive tests may well be useful for the identification of training and development potential and entry-level ability, but the importance of tests which measure personality, attitudes and values cannot be ignored.

Although the application of psychometric tests and other assessment techniques in South Africa have been sharply criticised of cultural bias, it should be borne in mind that the so-called "rainbow nation" functions in a culturally biased environment. Hartladge, Lucas and Godwin (1976) tested 100 black, culturally disadvantaged males with culturally biased and unbiased (Raven) tests and found that a more culture-fair test was unable to predict academic achievement better than the biased tests. The research was done in the United States of America, therefore this finding can probably be ascribed to the absence of language problems which South African psychologists are faced with. It would, on the other hand, not be feasible to remove language from test batteries for the selection of employees who need to be exposed to training courses in which instruction is given in a language other than the trainee's mother tongue. Psychometric testing in South Africa may therefore, never achieve the aim of culture fairness unless measurement instruments are designed to measure task and psychological attributes needed to adapt to specific work environments. Westernised values and personal attributes which support those values (eg. competitiveness and work ethic) would for example, be more important for dynamic, competitive organisations than those which thrive on benign gestures. The Standard Raven Matrices Test would also, regardless of its culture-reduced nature, not be suitable for identifying training potential among literate blacks. McLaurin and Farrar (1973) found that the Standard Raven Test yields low to moderate correlations with other intelligence tests when applied to under-graduate students. The opposite holds true when the test is applied to pupils (cf. Owen, 1992).

The results of the study clearly contradict the findings of researchers which follow the classical approach to the study of intelligence in which it is attempted to explain work performance and "social worth" by means of a so-called $g$ factor. This raises serious questions regarding the functionality of " $g$ " in the prediction of work performance in that it would not be possible to state that a person with an IQ of say, 120 would perform better than the person with an IQ of 90. The large error variance involved in using cognitive ability for the prediction of psychological readiness to perform, suggests some empirical support for a more radical approach to the study of intelligence in which the notion of a $g$-factor is rejected (see Snell, 1996). This school led by Gardner (1983), argues for seven distinct intelligences.

Logical-mathematical intelligence is the ability to mentally process logical problems and equations. This does not require verbal articulation, because complex problems can be solved mentally, and articulated afterwards. Each individual also has a different musical ability, but there are even people who are totally amusical, yet continue to have normal and successful lives. Musical intelligence does not seem to be an obvious form of intellect such as logical ability and appears to function independently from other forms of intelligence. Intra-personal intelligence is the ability to understand the "self", who we are, what feelings we have, and why we are like that. A strong intra-personal intelligence leads to self-esteem, self-enhancement and a strength of character that can be used to solve internal problems. Interpersonal intelligence refers to the ability to interact with others, understand people and interpret their behaviours. This includes the ability to recognize contrasts in moods, temperaments, motivations and intentions. BodilyKinesthetic intelligence is a natural sense of how the body should act and react in demanding, physical situations. Some researchers dismiss physical control as a form of intelligence, but Gardner maintains that bodily-kinesthetic ability does indeed deserve recognition. Spatial intelligence is most commonly seen in how people comprehend shapes and images in three dimensions. This is utilized to perceive and interpret that which may or may not physically be seen.

The problems regarding cross-cultural comparability of tests and the research findings regarding the importance of psychological readiness in the work situation, suggest that alternative assessment techniques may be worthwhile exploring. The Psychological Readiness Scale which was used in this study can for example, be refined by observing how employees react to job-related problems (as in the case of assessment centres). Such observations can then be operationalised by developing items to measure specific behaviours related to the broader aspects of psychological readiness which are measured by the Psychological Readiness Scale.

\section{REFERENCES}

Abrahams, J. (1994). The cross-cultural comparability of personality tests in South Africa: Is it possible? Paper presented at the Congress on Psychometrics for Psychologists and Personnel practitioners of the Society for Industrial Psychology. 13-14 June.

Argyris, C. (1962). Interpersonal competence and organizational effectiveness. Homewood, Illinois.: Dorsey.

Blank, W., Weitzel, J., \& Green, S.G. (1986). Situational leadership theory: A test of underlying assumptions. Proceedings of the Academy of Management, 384.

Blank, W., Weitzel, J., \& Green, S.G. (1988). A measure of Psychological Maturity. Group and Organization Studies, 13(2) 225-235.

Campbell, J., \& Pritchard, R. (1976). Motivation theory in industrial and organizational theory. In M.D. Dunnete (Ed.) Handbook of industrial and organizational psychology. (pp. 63130) Chicago: Rand McNally.

Carpenter, P.A., Just. M.A., \& Shell, P. (1990). What one intelligence test measures: A theoretical account of the processing in the Raven Progressive Matrices Test. Psychological review, 97(3) 404-431.

Case, J. (1996). Is the Bell Curve statistically sound? [Online]. Available: http//www.siam.org/siamnews/bookrevs/ case195.htm.

Elias, M. (1996). Psychological Experts find fault with "Bell Curve". [Online]. Available: http//www.usatoday.com/life/ health/chso64.htm

Hartladge, L. C., Lucas, T.L., \& Godwin (1976). Culturally biased and culuture-fair tests correlated with school performance in culturally disadvantaged children. Journal of Clinical Psychology. 32(3), 658-660.

Hernstein, R.J. and Murray, C. (1994). The bell curve: Intelligence and Class Structure in American Society. New York: Free Press.

Hersey, P., \& Blanchard, K.H. (1980). The essentials of situational leadership. California: Leadership Studies.

Jöreskog, K.G., \& Sörbom. (1993). Lisrel 8: Structural equation modeling with the SIMPLIS command language. Chicago: Scientific Software.

Maslow, A.H. (1954). Motivation and personality. New York: Harper and Row.

McLaurin, W.A., \& Farrar, W.S. (1973). Validities of the progressive matrices test against IQ and grade point average. Psychological Reports, 32(3), 803-806. 
Mc Kenna, F.P. (1984). Measures of field dependence: cognitive style or cognitive ability? Journal of Personality and Social Psychology, 47, 593-603.

McClelland, D.C. (1961). The achieving society. New Jersey: Van Nostrand.

Metzler, D. (1995). The dishonest claim of Genetic Racial IQ Differences. [Online]. Available: http://www2.pitt.edu/ genec/doug.html.

Owen, K. (1992). The suitability of Raven's Standard Progressive Matrices for various groups in South Africa. Personality and Individual differences, 13 (2), 149-159.

Porter, L., \& Lawler, E.E. (1968) Managerial attitudes and performance. New York: Irwin-Dorsey.

Rogers, T.B. (1996). Mainstream Science on Intelligence. [Online]. Available: http//psycserv.psych.ucalgary.ca/course/psyc331/ manifest.htm

Shell, L.S. (1996). The Bell Curve [Online]. Available: http// www.whitehurst.sbsb.edu/ppsy104/bellcurve.htm

Vecchio, R.P. (1987). Situational Leadership theory: An examination of a prescriptive theory. Journal of Applied Psychology, 72 (3) 444-451.

Vroom, V. (1964). Work and motivation. New York: John Wiley. 